\title{
COMPARATIVE RETROSPECTIVE STUDY ON ANAESTHESIA APPROACHES FOR LUMBAR SPINE SURGERY
}

\author{
Rangalakshmi S1, Praveen B. Halagunaki², Roshankumar B. $N^{3}$ \\ 1 Professor, Department of Anaesthesiology, Rajarajeswari Medical College and Hospital, Bangalore. \\ 2Junior Resident, Department of Anaesthesiology, Rajarajeswari Medical College and Hospital, Bangalore. \\ 3 Professor, Department of Orthopaedics, Rajarajeswari Medical College and Hospital, Bangalore.
}

\begin{tabular}{l}
\hline ABSTRACT \\
OBJECTIVE \\
Lumbar spinal surgeries have been performed with either spinal or general anaesthesia. In this study, we aimed to evaluate the \\
superiority of either spinal or general anaesthesia on lumbar spine surgery.
\end{tabular}

\section{METHODS}

After approval of institutional ethical committee, we retrospectively analysed 270 patients (ASA I and II) undergoing surgery of lumbar spine from 2009 to 2015 by one surgeon. Of these 150 patients underwent general anaesthesia with controlled ventilation, 120 patients were offered spinal anaesthesia with conscious sedation. Patient records were reviewed to obtain demographic features, type of anaesthesia, baseline heart rate, mean arterial pressure, intraoperative maximum heart rate, mean arterial pressure, duration of surgery, amount of intravenous fluids, intraoperative blood loss, incidence of perioperative complications such as bleeding, nausea, vomiting, hypotension, bradycardia, and postoperative analgesic consumption.

\section{RESULTS}

Patient characteristics including baseline/intraoperative mean arterial pressure and heart rate values did not differ between groups. However, the spinal anaesthesia group experienced significantly shorter durations in the operating room and had a lower incidence of nausea, vomiting. Analgesic consumptions in general anaesthesia group was significantly higher than in spinal anaesthesia group.

\section{CONCLUSION}

The present study revealed that spinal anaesthesia is a safe and effective alternative to general anaesthesia for patients undergoing single level or two level lumbar laminectomy, discectomy, or even instrumentation below L2 level and has the advantage of decreased nausea, antiemetic, analgesic requirements, and fewer complications. It also ensures better postoperative recovery when compared to general anaesthesia.

\section{KEYWORDS}

Anaesthesia, Spinal, General, Discectomy, Retrospective Studies.

HOW TO CITE THIS ARTICLE: Rangalakshmi S, Halagunaki PB, Roshankumar BN. Comparative retrospective study on anaesthesia approaches for lumbar spine surgery. J. Evolution Med. Dent. Sci. 2016;5(60):4217-4220, DOI: 10.14260/jemds/2016/962

\section{INTRODUCTION \\ Application of regional anaesthetics is widely preferred for lower extremity surgery, but general anaesthesia is used almost exclusively in spine surgery. The broad preference for general anaesthesia does not appear to be based on any scientifically or clinically established superiority rather more on surgeon bias and perhaps lack of exposure to the option of spinal anaesthesia. The debate regarding regional anaesthesia over general anaesthesia arises for lower thoracic and lumbar surgeries wherein also till recently general anaesthesia was exclusively preferred by most surgeons and anaesthetists. Of late, interest has been generated in the alternative use of regional anaesthesia for surgeries involving the lumbar spine. Additionally, the main reasons leading to a tendency towards}

Financial or Other, Competing Interest: None.

Submission 07-06-2016, Peer Review 14-07-2016,

Acceptance 19-07-2016, Published 28-07-2016.

Corresponding Author:

Dr. Praveen B. Halaguanki,

Junior Resident,

Department of Anaesthesiology,

Rajarajeswari Medical College and Hospital,

Kambipura, Kengeri Hobli,

Bangalore-560074.

E-mail: dr.praveenh@gmail.com

DOI: $10.14260 /$ jemds/2016/962 the use of general anaesthesia are associated with a higher acceptance by patients and the ability to perform longer operations with a secured airway in the prone position.

In contrast with general anaesthesia, spinal anaesthesia reduces blood loss, improves the view in the operating field by decreasing venous blood pressure, and can lead to a decrease in the length of inpatient stays and overall costs.1-3 Though recent controlled trials showed distinct results, there remains no consensus on the appropriate anaesthesia method for lumbar disc surgery.4-5

Disadvantage of regional anaesthesia is the inability to resuscitate and administer CPR in any eventuality. Prone intubation is very difficult if not impossible even in experienced hands. The surgeon cannot test the integrity of the spinal cord at the end of surgery due to the motor block. Patients sometimes experience severe discomfort due to coughing or hiccups, which is again difficult to treat in the prone position. The other important medicolegal aspect is the attribution of postoperative neurological deficit (Strictly, the surgeon's domain) to the anaesthesiologist's spinal anaesthesia!!.

The primary goal of this study is to investigate the efficiency of spinal anaesthesia in one-two level lumbar discectomy and laminectomy. Secondary goal is to report the retrospective analyses of 270 patients in whom spinal anaesthesia was used in the great majority of patients to assess 
the perioperative outcomes of spinal and general anaesthesia for elective lumbar discectomy and laminectomy.

\section{METHODS}

After obtaining approval from the Ethical Committee, patients with ASA I, II, grade who underwent one level and two level elective lumbar discectomy and laminectomy for lumbar disc herniation at the L4-L5 or L5-S1 levels were identified in the period between January 2009 and January 2015 in the Rajarajeswari Medical College and Hospital, Bangalore and included in the study.

The patients underwent surgery with either a general or a spinal anaesthesia. Patients who received general anaesthesia were administered inj. Propofol 2-3 mg/kg intravenous (IV), inj. fentanyl $1.5-2 \mathrm{mcg} / \mathrm{kg}$ IV, and inj. vecuronium bromide 0.1 $\mathrm{mg} / \mathrm{kg}$ IV in induction, and sevoflurane 1-2\%, 50 N20 - \% 50 02 with inj. vecuronium $1 \mathrm{mg}$ in maintenance of anaesthesia and patients in the spinal group were administered spinal anaesthesia with $3.2 \mathrm{~mL} 0.5 \%$ bupivacaine along with Inj. buprenorphine 75 to $100 \mathrm{mcg}$ (Depending on the weight of the patient). After administration of spinal anaesthesia, the patient was kept in the supine position till the level of sensory block reached T6-T4. At the same time, a continuous infusion was started with Inj. dexmedetomidine $0.5 \mathrm{mcg} / \mathrm{kg} / \mathrm{hr}$. All surgical procedures were performed with same surgeon with the patient placed in the prone position.

Patient records were reviewed to obtain demographic features (Age, gender, weight, height, Body Mass Index [BMI], American Society of Anaesthesia Score [ASA], type of anaesthesia (General or spinal anaesthesia), baseline Heart Rate (HR), Mean Arterial Pressure (MAP), intraoperative maximum HR and MAP, duration in the operating room, amount of intravenous fluids, estimated blood loss (Either greater than or less than $400 \mathrm{~mL}$ ), analgesic consumption, and incidence of perioperative complications such as bleeding, nausea-vomiting, hypotension, and bradycardia. The incidence of Post-Dural Puncture Headache (PDPH) was also collected for those who received spinal anaesthesia. Patients those received spinal anaesthesia were gathered in Group Spinal (SA), and those received general anaesthesia were in Group General (GA).

\section{STATISTICAL ANALYSIS}

Quantitative data were presented as the means and standard deviation and qualitative data as the frequency and percentage. Comparisons between groups for qualitative data were conducted by using chi-square test and for quantitative data by Mann-Whitney U test. The statistical software SAS 9.2, SPSS 15.0, Stata 10.1, MedCalc 9.0.1, Systat 12.0, and R environment ver.2.11.1 were used for the analysis of the data. Statistical significance for all analyses was set as $\mathrm{p}<0.05$.

\section{RESULTS}

\begin{tabular}{|c|c|c|c|}
\hline & $\begin{array}{c}\text { Spinal } \\
\text { Anaesthesia } \\
\text { Group (SA) } \\
\text { n (Mean } \pm \\
\text { SD) }\end{array}$ & $\begin{array}{c}\text { General } \\
\text { Anaesthesia } \\
\text { Group (GA) } \\
\text { n (Mean } \pm \\
\text { SD) }\end{array}$ & P-value \\
\hline $\begin{array}{c}\text { Number of } \\
\text { Patient }\end{array}$ & 150 & 120 & 0.740 \\
\hline Age & $49.61 \pm 12.18$ & $46.97 \pm 9.13$ & 0.247 \\
\hline
\end{tabular}

\begin{tabular}{|c|c|c|c|}
\hline Gender & & & \\
\hline Male (n, \%) & $80(53.38 \%)$ & $73(60.83 \%)$ & 0.974 \\
\hline $\begin{array}{c}\text { Female } \\
\text { (n, \%) }\end{array}$ & $70(46.62 \%)$ & $47(39.17 \%)$ & 0.950 \\
\hline BMI & $24.88 \pm 2.3$ & $25.22 \pm 2.8$ & 0.613 \\
\hline Baseline HR & $80.54 \pm 12.34$ & $76.41 \pm 13.64$ & 0.072 \\
\hline $\begin{array}{c}\text { Baseline } \\
\text { MAP }\end{array}$ & $92.22 \pm 9.95$ & $89.43 \pm 11.97$ & 0.197 \\
\hline ASA(I/II)\% & $44.6 / 56.4$ & $52.2 / 48.8$ & $0.113^{\dagger}$ \\
\hline $\begin{array}{c}\text { Duration in } \\
\text { Operating } \\
\text { Room } \\
\text { (Mins) }\end{array}$ & $77.21 \pm 21.52$ & $98.2 \pm 44.23$ & $0.002^{* \#}$ \\
\hline \multicolumn{4}{|c|}{ Table 1: Demographic Data } \\
\hline
\end{tabular}

*: $\mathrm{p}<0.05, \dagger$ : Fisher's exact test, \#: Mann-Whitney U test

\begin{tabular}{|c|c|c|c|}
\hline & $\begin{array}{c}\text { Spinal } \\
\text { Anaesthesia } \\
\text { Group (SA) }\end{array}$ & $\begin{array}{c}\text { General } \\
\text { Anaesthesia } \\
\text { Group (GA) }\end{array}$ & $\begin{array}{c}\text { P- } \\
\text { value }\end{array}$ \\
\hline $\mathrm{n}$ (Mean \pm SD) & $\mathrm{n}$ (Mean \pm SD) & \\
\hline $\begin{array}{c}\text { Intra- } \\
\text { operative } \\
\text { maximal HR }\end{array}$ & $76.18 \pm 15.97$ & $72.67 \pm 11.34$ & 0.103 \\
\hline $\begin{array}{c}\text { Intra- } \\
\text { operative } \\
\text { maximal } \\
\text { MAP }\end{array}$ & $80.82 \pm 12.33$ & $82.04 \pm 12.76$ & 0.991 \\
\hline $\begin{array}{c}\text { Intravenous } \\
\text { fluids }\end{array}$ & $1711.22 \pm 568.38$ & $1579.41 \pm 614.26$ & 0.162 \\
\hline \multicolumn{3}{|c|}{ Table 2: Intraoperative Outcome } \\
\hline
\end{tabular}

Mann-Whitney U test

\begin{tabular}{|c|c|c|c|}
\hline & $\begin{array}{c}\text { Spinal } \\
\text { Anaesthesia } \\
\text { Group (SA) }\end{array}$ & $\begin{array}{c}\text { General } \\
\text { Anaesthesia } \\
\text { Group (GA) }\end{array}$ & $\begin{array}{c}\text { P- } \\
\text { value }\end{array}$ \\
\hline & $\begin{array}{c}\text { n (\%) } \\
\text { (Mean } \pm \text { SD) }\end{array}$ & $\begin{array}{c}\text { n (\%) } \\
\text { (Mean } \pm \text { SD) }\end{array}$ & \\
\hline Bleeding & $3 / 150(2 \%)$ & $5 / 120(4.1 \%)$ & 0.197 \\
\hline $\begin{array}{c}\text { Nausea- } \\
\text { vomiting }\end{array}$ & $\begin{array}{c}25 / 150 \\
(16.6 \%)\end{array}$ & $\begin{array}{c}36 / 120 \\
(30.2 \%)\end{array}$ & $0.001^{* \neq}$ \\
\hline Hypotension & $\begin{array}{c}35 / 150 \\
(23.5 \%)\end{array}$ & $\begin{array}{c}18 / 120 \\
(15 \%)\end{array}$ & 0.241 \\
\hline Bradycardia & $\begin{array}{c}22 / 150 \\
(14.6 \%)\end{array}$ & $\begin{array}{c}12 / 120 \\
(10.0 \%)\end{array}$ & 0.532 \\
\hline PDPH & $\begin{array}{c}2 / 150 \\
(1.33 \%)\end{array}$ & \\
\hline $\begin{array}{c}24 \text { hours } \\
\text { analgesic }\end{array}$ & $95.37 \pm 10.46$ & $140.58 \pm 19.53$ & $<0.01^{*} \S$ \\
consumption & \multicolumn{3}{|c|}{} \\
\hline \multicolumn{4}{|c|}{ Table 3: Postoperative Outcomes } \\
\hline
\end{tabular}

*: p<0.05, ‡: Chi-Square test, Fisher exact test, §: MannWhitney U test.

Demographic data results showed there were no significant differences between the groups in age, ASA physical status, baseline MAP, and HR (Table 1). Patients who received spinal anaesthesia was heavier than the general anaesthesia patients. Duration of surgery was significantly shorter in the SA group $(p=0.002)$. 
Intraoperative maximal HR, intraoperative maximal MAP, and the amount of intraoperative fluid usage were not significantly different between groups (Table 2). Analgesic consumption in GA was significantly higher than in SA $(p<0.01)$. Nausea-induced vomiting frequency was higher in the GA compared to the $S A(p<0.01$; Table 3$)$.

\section{DISCUSSION}

The present study revealed that operating room durations in the spinal anaesthesia group were shorter than in the general anaesthesia group. The analgesic consumption after spinal anaesthesia was substantially lower associated with complications, nausea-vomiting had a higher prevalence in the general anaesthesia group.

Regional anaesthesia and general anaesthesia are both appropriate anaesthetic techniques for lumbar discectomy. McLain et al. concluded that spinal anaesthesia was as safe and effective as general anaesthesia for patients undergoing lumbar laminectomy. Potential advantages of spinal anaesthesia include a longer analgesia duration, decreased nausea, antiemetic and analgesic requirements, and fewer complications. Successful surgery can be performed using either anaesthesia type.[6]

Several studies comparing spinal anaesthesia and general anaesthesia in lumbar disc surgery have reported spinal anaesthesia as the preferred method for lumbar spine surgery. ${ }^{[1,5-8]}$ In relation, some centres have been routinely performing regional anaesthesia for lumbar laminectomy and discectomy. ${ }^{[3]}$ As a consequence of this current study, spinal anaesthesia was more frequently used anaesthetic approach. To decide the most effective method, a recent randomised clinical trial by Attari et al revealed that SA was superior to GA. Spinal anaesthesia decrease severity of postoperative pain and analgesic consumption, decreased blood loss, better perioperative haemodynamic stability without additional side effect. These factors resulted in higher satisfaction rates for the surgeon and patients.[5]

Spinal anaesthesia may lead to a reduction in blood loss associated with vasodilation and hypotension produced by sympathetic blockade and less distension of epidural veins resulting from lower intrathoracic pressure. Study suggests that SA maybe superior to GA both intraoperatively and postoperatively for lumbar spine procedures lasting less than 2 h.[2]

A retrospective analysis by Tetzlaff et al demonstrated that spinal anaesthesia was a safe and effective alternative to general anaesthesia for elective lumbar spine surgery with reduced perioperative complication rates. They concluded that spinal anaesthesia could be an excellent choice for lumbar spine surgery. ${ }^{[9]}$ Additionally, reduced surgical time and blood loss in spinal anaesthesia were reported by Jellish et al whose results were in agreement with the present study.[2]

However, to show the amount of blood loss from the data in this study can be difficult, which can be related to the uncertainty of the data taken in a retrospective analysis. Only in 8 cases, three that used SA and the other five with GA showed blood losses over $400 \mathrm{~mL}$, which was considered the threshold of blood loss in this study.

Various studies have also shown that spinal anaesthesia provided shorter anaesthesia durations, decreased nausea incidence, analgesic consumption, and was associated with fewer total side effects. $[2,7,8,10]$ Nausea and vomiting are already common problems that anaesthesiologists must cope with during the postoperative period.

These symptoms appear to be associated with many factors such as age, gender, ASA, obesity, duration of anaesthesia, use of volatile anaesthetics, nitrous oxide, and intraoperative or postoperative opioids.[11,12] In the current study, demographic data were well matched between groups; therefore, the main variables affecting the occurrence of nausea and vomiting in the GA are most likely anaesthesiarelated factors. First, N2O use can be blamed for leading to an increased rate of nausea-vomiting. Second, the GA had a higher severity of pain and required an increased amount of opioids in the postoperative period. Hence, opioids associated with sensitising the vestibular apparatus to movement could raise the incidence of nausea and vomiting.[2]

In the present study, lower analgesic requirements in the SA during the postoperative period can be explained by two mechanisms. Spinal anaesthesia may lead to a reduced sense of pain by inhibiting afferent nociceptive pathways that result from pre-emptive analgesia.[13]

Additionally, residual sensory blockade may remain after the spinal anaesthesia process, which may decrease analgesic consumption.[14] Urinary retention has been observed with spinal anaesthesia in the current study. Buprenorphine is a mixed agonist antagonist narcotic with high affinity at both $\mu$ and kappa opiate receptors. Buprenorphine is compatible with CSF and produces no adverse reactions when administered intrathecally. At low doses, buprenorphine produces effective and prolonged duration of action with minimal side effects making it a suitable choice for intrathecal administration. [15] Sen M. in his study found that buprenorphine group had prolonged postoperative analgesia, minimal disturbance of consciousness and respiration, and buprenorphine is an effective analgesic suitable for the management of postoperative pain in elderly patients.[16]

Dexmedetomidine infusion has been found to prolong the duration of analgesia and without prolong motor blockade in the present study. Lugo et al[17] in their study noted prolongation of sensory block and duration of analgesia without significant effect on motor block while using $1 \mathrm{mcg} / \mathrm{kg}$ bolus followed by $0.5 \mathrm{mcg} / \mathrm{kg} / \mathrm{h}$ infusion of dexmedetomidine. Al-Mustafa et al[18] also observed similar findings in their study and in addition there was prolongation of motor blockade with a similar dose of dexmedetomidine. Haemodynamic response following dexmedetomidine infusion depends upon the dose and speed of infusion. A sequence of transient hypertension with reflex bradycardia followed by hypotension is seen with higher dose and rapid infusion.[19,20] The subsequent decrease in heart rate and blood pressure maybe due to decrease in central sympathetic outflow.[20] as we used only 0.5 $\mathrm{mcg} / \mathrm{kg} / \mathrm{hr}$, so there was minimal decrease in heart rate and blood pressure in patients receiving spinal anaesthesia with dexmedetomidine infusion in our study similar to observations of other authors. ${ }^{[18]}$

Furthermore, the significant conclusion for this study is that discectomies with spinal anaesthesia have shorter durations in the operating room. This time difference is due to the elapsed time needed to perform spinal anaesthesia and also having no time lost for extubation and achieve acceptable level of consciousness. In the absence of satisfactory differences between spinal anaesthesia and general anaesthesia, cost associated with the duration could be judged 
to be an acceptable reason to decide on an optimum option. [21] In a clinical evaluation, Wodlin et al. reported that spinal anaesthesia is considered cost effective compared to general anaesthesia in abdominal hysterectomy procedures. ${ }^{[22]}$ Moreover, Gonano et al. described spinal anaesthesia as a costeffective alternative to general anaesthesia after an evaluation in the postoperative period for hip and knee replacement patients.[23] Clinical directors have typically focused on the single issue of maximizing operating room efficiency and have indicated that reducing waiting times plays an important role in solving this problem. ${ }^{[24]}$ Similar to these results, the present study associated the duration differences in the operating room with costs and the data suggests that SA appeared to provide a lower cost than GA. It can be speculated that spinal anaesthesia may lead to greater cost effectiveness in lumbar discectomies.

This study has few limitations. First, long-term complications could not be obtained and assessed associated with the lack of the data. Second, the patient satisfaction is one of the important assessment value for spinal anaesthesia; however; it could not be evaluated.

\section{CONCLUSION}

Spinal anaesthesia seems to be a cost-effective technique associated with shorter durations in the operating room and providing a lower nausea-vomiting incidence with discectomy procedure. Additionally, further prospective studies are needed to elucidate the superiority of spinal anaesthesia compared to general anaesthesia in lumbar discectomies.

\section{REFERENCES}

1. Nicassio $N$, Bobicchio $P$, Umari $M$, et al. Lumbar microdiscectomy under epidural anaesthesia with the patient in the sitting position: a prospective study. J Clin Neurosci 2010;17(12):1537-40.

2. Jellish WS, Thalji Z, Stevenson K, et al. A prospective randomised study comparing short- and intermediateterm perioperative outcome variables after spinal or general anaesthesia for lumbar disk and laminectomy surgery. Anaesth Analg 1996;83(3):559-64.

3. De Rojas J0, Syre P, Welch WC. Regional anaesthesia versus general anaesthesia for surgery on the lumbar spine: a review of the modern literature. Clin Neurol Neurosurg 2014;119:39-43.

4. Sadrolsadat SH, Mahdavi AR, Moharari RS, et al. A prospective randomised trial comparing the technique of spinal and general anaesthesia for lumbar disk surgery: a study of 100 cases. Surg Neurol 2009;71(1):60-5.

5. Attari MA, Mirhosseini SA, Honarmand A, et al. Spinal anaesthesia versus general anaesthesia for elective lumbar spine surgery: a randomised clinical trial. J Res Med Sci 2011;16(4):524-9.

6. McLain RF, Kalfas I, Bell GR, et al. Comparison of spinal and general anaesthesia in lumbar laminectomy surgery: a case-controlled analysis of 400 patients. J Neurosurg Spine 2005;2(1):17-22.
7. McLain RF, Bell GR, Kalfas I, et al. Complications associated with lumbar laminectomy: a comparison of spinal versus general anaesthesia. Spine (Phila Pa 1976) 2004;29(22):2542-7.

8. Kara I, Celik JB, Oc B, et al. Comparison of spinal and general anaesthesia in lumbar disc surgery. Journal of Neurological Sciences 2011;28(4):487-96.

9. Tetzlaff JE, Dilger JA, Kodsy M, et al. Spinal anaesthesia for elective lumbar spine surgery. J Clin Anaesth 1998;10(8):666-9.

10. Rodriguez JP, Tambe A, Dua R, et al. Spinal or general anaesthesia for lumbar spine microdiscectomy surgery. does it matter? The Internet Journal of Spine Surgery 2006;3(2).

11. Gan TJ. Risk factors for postoperative nausea and vomiting. Anaesth Analg 2006;102(6):1884-98.

12. Watcha MF, White PF. Postoperative nausea and vomiting. Its aetiology, treatment, and prevention. Anaesthesiology 1992;77(1):162-84.

13. Covino BG. Rationale for spinal anaesthesia. Int Anaesthesiol Clin 1989;27(1):8-12.

14. Pflug AE, Aasheim GM, Foster C. Sequence of return of neurological function and criteria for safe ambulation following subarachnoid block (spinal anaesthetic). Can Anaesth Soc J 1978;25(2):133-9.

15. Miller RD. Miller's anaesthesia. Chapter 27. 7th edn. Philadelphia: Elsevier 2010:p.809.

16. Sen M. Intrathecal buprenorphine for postoperative analgesia in orthopaedic surgery. J Indian Med Asso 1992;90(1):5-6.

17. Lugo VW, Gomez RIA, Corral RC, et al. Intravenous dexmedetomidine versus intravenous clonidine to prolong bupivacaine spinal anaesthesia. A double blind study. Anaesthesia en Mexico 2007;19(3):143-6.

18. Al-Mustafa MM, Badran IZ, Abu-Ali HM, et al. Intravenous dexmedetomidine prolongs bupivacaine spinal analgesia. Middle East J Anaesthesiol 2009;20(2):225-31.

19. Mason KP, Zurakowski D, Zgleszewski S, et al. Incidence and predictors of hypertension during high-dose dexmedetomidine sedation for paediatric MRI. Paediatr Anaesth 2010;20(6):516-23.

20. Sudheesh K, Harsoor SS. Dexmedetomidine in anaesthesia practice: a wonder drug? Indian J Anaesth 2011;55(4):323-4.

21. Chakladar A, White SM. Cost estimates of spinal versus general anaesthesia for fractured neck of femur surgery. Anaesthesia 2010;65(8):810-4.

22. Wodlin BN, Nilsson L, Carlsson P, et al. Cost-effectiveness of general anaesthesia vs spinal anaesthesia in fast-track abdominal benign hysterectomy. Am J Obstet Gynaecol 2011;205(4):326.e1-7.

23. Gonano C, Leitgeb U, Sitzwohl C, et al. Spinal versus general anaesthesia for orthopaedic surgery: anaesthesia drug and supply costs. Anaesth Analg 2006;102(2):524-9.

24. O'Sullivan CT, Dexter F. Assigning surgical cases with regional anaesthetic blocks to anaesthetists and operating rooms based on operating room efficiency. AANA J 2006;74(3):213-8. 